\title{
The Truth Behind the Amber Teething Necklaces
}

\author{
Merve Aksoy* \\ Health Sciences University, Faculty of Gulhane Dentistry, Department of Pedodontics, Ankara, Turkey
}

*Corresponding author: Merve Aksoy, Health Sciences University, Faculty of Gulhane Dentistry, Department of Pedodontics, Ankara, Turkey.

Received Date: August 16, 2021

Published Date: September 13, 2021

\begin{abstract}
Teething symptoms and patients' way to overcome these complaints differs due to various factors. Among the well-known traditional methods and analgesic prescriptions, amber teething necklaces started to gain popularity. Skin contacted amber usage is believed to perform an analgesic effect, and this statement stands behind using these accessories as a teething remedy. However, is it all true or not? This mini-review aimed to state a decision on using amber accessories as a teething remedy and warn the practitioners about the potential hazards of these accessories.
\end{abstract}

\section{Introduction}

The eruption of the first teeth through the oral environment is called the deciduous dentition period. This period starts approximately in the first six months after the birth and continues until the age of 2.5-3. It is controversial whether the mostly seen teething complaints, such as pain, restlessness, and fever, have a direct relationship with tooth eruption or not. The teething period can be considered the most troubling time of the first years of life for families, babies, and children [1-3]. Some researchers argue that the deciduous dentition period intersects with the process in which the passive immunity terminates and the active immunity starts to form. Therefore, the resistance to infection decreases and the clinical findings of infectious diseases in this period may interfere with dentition disorders. Even if there is a contrary belief, since it is an inflammatory process involving production-destruction events, it is usual to see the signs of inflammation, usually mild, in this period [4].

The symptoms associated with the dentition period can be itching in the gums, restlessness, pain, sleep problems, loss of appetite, increased saliva, diarrhea, fever, and rash at the angelus of the mouth. It is unknown how much of these symptoms are related to tooth eruption individually, and it seems that there is no definite judgment on this subject. According to the literature reviews, symptoms such as fever, runny nose, and cough are not related to the dentition. However, it is known that general pediatricians, whom pediatric patients frequently consult due to these problems, associate these mild infection findings with dentition. It is prevalent among families to associate the symptoms of an infectious factor, including high fever, with the tooth-eruption period. As much as patients in teething period apply to the hospitals by the symptoms of infectious disease, the pediatric specialists and general practitioners tend to believe and try to treat the patients as the symptoms are related to the dentition period according to the belief of the patients [5].

The way families and physicians overcome the symptoms seen in the dentition period varies. The methods preferred by the families may differ due to the social knowledge, culture, and education level of the family. Among these methods, the most preferred practice is using teether with or without cold gel- 
liquid, refrigerated objects, cold fruits and vegetables, and some essential oils. It may also be possible to use paracetamol-containing analgesics and the application of over-the-counter (OTC) dental gels containing anesthetic in line with or without the doctor's/dentist's recommendations and prescriptions [5-8]. Today, another popular method with the influence of advertising and user suggestions on social media is amber necklaces and accessories, which are called dental necklaces in the market [9]. The best-recommended properties of amber necklaces are attributed to succinic acid, which is believed to have anti-inflammatory properties. In the recent studies, it was stated that the release of succinic acid from the beads could not perform an antibacterial effect, and it was also mentioned that these accessories might create a surface for bacterial colonization [10-11].

In a previous study, the release of succinic acid from amber beads was analyzed. Amber beads were immersed in phosphate-buffered solution at $\mathrm{pH} 5.5-37^{\circ} \mathrm{C}$ or octanol, which mimics the hydrophobic environment. It was found that the amount of succinic acid released from the beads was far below than the level that exhibits anti-inflammatory activity, so it did not show an anti-inflammatory effect. It was also found that very high levels of succinic acid could suppress the number of inflammatory cytokines. However, these concentrations have been found to reduce the $\mathrm{pH}$ to 3.4. At this $\mathrm{pH}$, it was observed that tissue cells undergo apoptosis which means this amount of succinic acid does not perform biocompatible properties. Besides, in the same study, it was observed that, although succinic acid did not show an anti-inflammatory effect, it caused an immunosuppressive effect by disrupting leukocyte and neutrophil functions [10].

Apart from the potential benefits of these accessories, there are also important disadvantages. These are the risks of strangulation and aspiration of beads, especially during the night sleep of the child/baby. Due to these potential life threats, the use of amber necklaces is prohibited in Canada [12-17]. In a case report published by Cox, et al. [14], a 4-month-old baby boy with no systemic disease applied to the health center because of petechiae on his face as a cause of sleeping at night with an amber necklace on his neck used for the first time, and this case was the first non-fetal infant strangulation observed due to the use of amber necklaces. In the same report, it was also mentioned that the parents of the patients were not warned about possible risks while using these products [14].

According to the results of a survey study including dentists, pediatric dentists, pediatricians, and family physicians, who investigated the level of recommendation for the use of amber necklaces by physicians, it was seen that only $8.5 \%$ of physicians recommended amber necklaces. It has been stated that the rate of medical doctors recommending this jewelry is higher than dentists and family physicians. As seen in this study, only a minimal number of dentists recommended using this jewelry to their patients [18]. Although no studies prove the praised beneficial properties of amber jewelry and accessories, which have become popular in the market as dental necklaces, the use of these accessories increases. In a questionnaire study measuring patients' satisfaction and utilization levels, every participant except 4 participants in a group of 29 people stated that amber necklaces relieved the pain and discomfort experienced by the children during the teething period. It has been stated that it is effective in sedating. It is thought that the high frequency of patients' preference for these jewelry does not match with any evidence that the product is beneficial. Also, one of the results of this survey is that the amber necklace vendors did not warn the users about the possible risks of the product [19].

Despite all these negative features, the use of amber necklaces in society increases mainly among people from high socialeconomical classes. The use of amber necklaces is widespread on social media, and people buy this jewelry by seeing the parents who use it for their children. In the studies conducted, it is seen that the vendors did not inform the parents about the possible risks of the use of amber necklaces. Still, when this information is given later, the parents stated that they would continue to use amber necklaces despite the risks described.

\section{Conclusion}

In conclusion, considering the information given, this review suggests that more information should be provided about the possible risks of this jewelry, which is marketed as an antiinflammatory teething necklace, and the sales and advertising of amber teething accessories should be limited.

\section{Acknowledgment}

None.

\section{Conflict of Interest}

The author declares no conflict of interest.

\section{References}

1. Wake M, Hesketh K, Allen M (1999) Parents beliefs about infant teething: a survey of Australian parents. J Paediatr Child Health 35: 446-449.

2. Çelen R, Taş Arslan F (2018) Teething process in babies and applications for the problems encountered in this process. Current Pediatrics 16: 181-186.

3. Bhavneet K (2012) Awareness of parents towards teething. Bangladesh J Med Sci 11: 40-43.

4. Wray D (1990) The torment of teething. Br Dent J 169: 1-7.

5. Owais AI, Zawaideh F, Al-Batayneh OB (2010) Challenging parents' myths regarding their children's teething. Int J Dent Hyg 8(1): 28-34.

6. Tsang AKL (2010) Teething, teething pain and teething remedies. International Dentistry SADJ 12(5): 48-61.

7. Kılınç G, Edem P, Günay T, Aydın A, Halıcıoğlu O, et al. (2015) Complaints and approaches of mothers about the eruption of their children's milk teeth. Turkey Clinics J Dental Sci 21(2): 90-94.

8. Plutzer K, Spencer AJ, Keirse MJNC (2012) How first-time mothers perceive and deal with teething symptoms: A randomised controlled trial. Child Care Health Dev 38: 292-299.

9. Strieder AP, Aguirre PE, Lotto M, Cruvinel AF, Cruvinel T (2019) Digital behavior surveillance for monitoring the interests of Google users in amber necklace in different countries. Int J Paediatr Dent 29: 603-614. 
10. Nissen MD, Lau ETL, Cabot PJ, Steadman JK (2019) Baltic amber teething necklaces: could succinic acid leaching from beads provide antiinflammatory effects? BMC Complement Altern Med 19: 1-162.

11. Machet P, Lanotte P, Giraudeau B, Leperlier M, Tavernier E, et al. (2016) Amber necklaces: reasons for use and awareness of risk associated with bacterial colonisation. Eur J Dermatol 26: 580-585.

12. Soudek L, McLaughlin R (2018) Fad over fatality? The hazards of amber teething necklaces. J Paediatr Child Health 23: 106-110.

13. Zigon G, Gregori D, Corradetti R (2006) Child mortality due to suffocation in Europe (1980-1995): A review of official data. Acta Otorhinolaryngol Ital 26: 154-161.

14. Cox C, Petrie N, Hurley KF (2017) Infant strangulation from an amber teething necklace. CJEM 19(5): 400-403.
15. Chin N, Berns SD (1995) Near-hanging caused by a toy necklace. Ann Emerg Med 26: 522-525.

16. Feldmann KW, Simms RJ (1980) Strangulation in childhood: epidemiology and clinical course. Pediatrics 65: 1079-1085.

17. Cyr C, Canadian Pediatric Society, Injury Prevention Committee (2012) Preventing choking and suffocation in children. Paediatr Child Health 17: $91-94$

18. Topal BG, Falay SB (2020) Do physicians recommend the use of amber jewelry for eruption symptoms? JCP 18(1): 63-73

19. Taillefer A, Casaoprana A, Cascarigny F (2012) Infantswearing teething necklaces [in french]. Arch Pediatr 19(10): 1058-1064. 